\title{
MOLECULARLY IMPRINTED POLYMER FOR THE BINDING AND RECOGNITION OF BASIC BLUE 41 DYE
}

\author{
ELISA GARZA MONTELONGO ${ }^{1}$, NANCY ADRIANA PÉREZ RODRÍGUEZ ${ }^{1}$, MARÍA GUADALUPE SÁNCHEZ \\ ANGUIANO ${ }^{1}$, BERNABÉ RIVAS QUIROZ ${ }^{* 2}$ AND PERLA ELIZONDO MARTÍNEZ *I \\ ${ }^{1}$ Universidad Autónoma de Nuevo León, Facultad de Ciencias Químicas, 66455, San Nicolás de los Garza, Nuevo León, México. \\ ${ }^{2}$ Universidad de Concepción, Facultad de Ciencias Químicas, Departamento de Polímeros, 4070386, Concepción, Chile.
}

\begin{abstract}
This study reports a novel imprinted molecular poly(ethylene terephatalate) (MIPBB ${ }_{41}$ ) for the binding and selective recognition of an azoic dye (basic blue 41 ) by a non-covalent imprinting approach. Basic blue $41\left(\mathrm{BB}_{41}\right)$ was chosen as the template molecule, acrylic acid-grafted poly(ethylene terephthalate) (PET- $g$-AA) and $N, N$ '-methylene-bis-acrylamide (MBA) were used as the functional polymer and crosslinking reagent respectively. To determine the binding capacity of MIPBB ${ }_{41}$, several adsorption studies were performed. The adsorption isotherm was described by the Langmuir model, and the maximum adsorption capacity of MIPBB ${ }_{41}$ toward basic blue 41 reached $144.8 \mathrm{mg} \mathrm{g}^{-1}$ in water at $\mathrm{pH} 6.2$. The fabricated MIP showed good recognition properties. In a further experiment, the adsorption capacity of the MIP was compared to the non-imprinted polymer (NMIP), and a recognition coefficient of 3.14 was obtained.
\end{abstract}

Keywords: Imprinted polymer, Recognition, Dye, Basic Blue 41.

\section{INTRODUCTION}

Pollution caused by the presence of azo dyes, such as basic blue 41, in the aqueous environment is of great importance because these molecules are considered to be genotoxic and carcinogenic, thus posing a threat to human health after they enter the food chain [1-5]; hence, their removal from wastewater has become an environmentally important issue.

Conventional treatment methods for these types of molecules, such as biodegradation, are often inefficient for the discoloration of the effluents containing the dye molecules. Furthermore, in the case of incomplete degradation, some of the generated by-products may be more harmful than the starting product [6].

Recently, adsorption has become increasingly important as a separation and extraction process and has become an effective option for water treatment, particularly for the removal of chemically stable organic compounds such as dyes [7-11].

A selective adsorption process must be performed for the separation of an organic compound from complex media, achieving adsorption is highly challenging. While different materials as brick residues [12], nanoporous silica [13] and zeolite [14] have been used to remove these contaminants from aqueous solutions, to obtain good results in the adsorption process, it is necessary to select an adsorbent that has high selectivity, high adsorption capacity and is reusable. Unfortunately, most adsorbents are expensive and exhibit low reusability and poor selectivity.

Molecularly imprinted polymers (MIPs) are materials that can selectively recognize a template molecule because they remember the shape and functionality of the target molecule [13-16]. These polymers have been widely used in different applications: sensors, drug carriers and adsorbents. Compared to other common adsorbents, MIPs have higher physical robustness, strength, resistance to elevated temperature and pressure and inertness toward acids, bases, metal ions and organic solvents. In addition, their synthesis is relatively inexpensive, and the polymers have a long storage life, maintaining their recognition capacity for several years at room temperature [16-20].

Therefore, in the present work, we decided to synthesize a molecularly imprinted polymer obtained by grafting acrylic acid onto poly(ethylene terephthalate) obtained from bottle waste, and crosslinking it with MBA. Then the MIP was imprinted with basic blue 41 as template molecule. The adsorption of basic blue 41 onto the MIPBB 41 was investigated in detail by measuring the adsorption isotherms. The efficient adsorption and selectivity of the MIP was demonstrated by studying the different rebinding capabilities of $\mathrm{BB}_{41}$ with other dye samples. The maximum adsorption capability of MIPBB $_{41}$ toward basic blue 41 reached $144.8 \mathrm{mg} \mathrm{g}^{-1}$ in water at $\mathrm{pH}$ 6.2. The obtained recognition coefficient was 3.14, indicating that the imprinted material effectively recognizes the template molecule.

\section{EXPERIMENTAL}

Grinding bottle grade PET was used with a particle size less than 60 micrometers. This material was washed with methanol for $6 \mathrm{~h}$ and then rinsed with distilled water prior to being filtered and dried at $70{ }^{\circ} \mathrm{C}$ for 5 days.

Acrylic acid (AA) and N,N'-methylene-bis-acrylamide (MBA) were used as the monomer and the crosslinking reagent, respectively; and were obtained from Sigma Aldrich with $99 \%$ of purity. Basic blue $41\left(\mathrm{BB}_{41}\right)$ was used as the template and was purchased from Sigma Aldrich with $40 \%$ of dye content. Standard grade methanol, reactive grade acetone, ammonium persulfate with $99 \%$ of purity and benzoyl peroxide with $99 \%$ of purity were also purchased from Sigma Aldrich. All of the chemicals were used without further purification unless otherwise described.

\section{Preparation of the polymer (MIPBB $\left.{ }_{41}\right)$}

First acrylic acid was grafted onto the PET structure: PET samples $(1 \mathrm{~g} \pm 0.1$ $\mathrm{mg}$ ) were impregnated with a $5 \%$ acetone solution of benzoyl peroxide. The samples were placed in a polymerization tube equipped with a mechanical stirrer, thermometer, nitrogen supply and a compensated pressure addition funnel containing $10 \mathrm{~mL}$ of acrylic acid. Acrylic acid was added at a rate of $0.2 \mathrm{~mL} / \mathrm{min}$, the reaction was carried out at $60{ }^{\circ} \mathrm{C}$ for $2 \mathrm{~h}$ under constant stirring.

PET- $g$-AA $(1.2 \mathrm{~g} \pm 0.1 \mathrm{mg})$ a $\mathrm{BB}_{41}$ solution $(20 \mathrm{~mL}, 20 \mathrm{mgL}-1)$ were stirred for $6 \mathrm{~h}$ at room temperature to prepare the pre-assembly solution. MBA (15 mmol) and ammonium persulfate (PSA, $0.1 \mathrm{~g}$ ) were successfully dissolved in the above solution, and then the mixture was purged with nitrogen for $5 \mathrm{~min}$ to displace the oxygen. Then, the polymerization reaction tube was sealed and allowed to proceed at $60{ }^{\circ} \mathrm{C}$ for $6 \mathrm{~h}$ with continuous stirring. Finally, the fabricated $\mathrm{MIPBB}_{41}$ was rinsed with methanol to remove the template and then dried under vacuum at $40{ }^{\circ} \mathrm{C}$ for $24 \mathrm{~h}$.

\section{Characterization}

Fourier transform-infrared spectroscopy (FT-IR) spectra were recorded in the range of $400-4000 \mathrm{~cm}^{-1}$ by using a PerkinElmer FT-IR spectrometer, model Spectrum 1. Differential scanning calorimetry (DSC) measurements were performed with a Netzsch DSC 204F1 differential scanning calorimeter. The samples were heated from 0 up to $300{ }^{\circ} \mathrm{C}$ at $10{ }^{\circ} \mathrm{C} / \mathrm{min}$ in nitrogen atmosphere, cooled to $0{ }^{\circ} \mathrm{C}$ at $10{ }^{\circ} \mathrm{C} / \mathrm{min}$, and then reheated from 0 up to $300{ }^{\circ} \mathrm{C}$ at the same rate. The sample morphology was observed using a scanning electron microscope (JEOL JSM-6380).

*Corresponding author email: elizondomr@uanl.edu.mx, brivas@udec.cl 


\section{Adsorption studies}

Each batch adsorption experiment was carried out using $\mathrm{MIPBB}_{41}(25 \mathrm{mg})$ dispersed in $\mathrm{BB}_{41}$ solution $(20 \mathrm{~mL})$ in a test tube with different initial concentrations varying from $10-1000 \mathrm{mgL}^{-1}$. The tubes were stirred at room temperature and $200 \mathrm{rpm}$ for $12 \mathrm{~h}$ in a shaking water bath (Thermo Scientific, Model 2872). The non-adsorbed dye concentration was measured by UV-Vis (Cintra 6) technique at $608 \mathrm{~nm}$ to determine the residual dye and to calculate the adsorption capacity of the polymer. The experiments were also carried out using NMIP as the adsorbent under the conditions described above.

\section{RESULTS}

\section{Grafting of acrylic acid onto PET}

PET- $g$-AA was synthesized by free radical solution polymerization. The effect of reaction conditions on the grafting parameters such as amount of initiator, monomer addition rate, reaction time and temperature were investigated. The variable temperature studies demonstrate that the grafting increased with increasing temperature because this factor increases the rates of initiation and propagation of the copolymerization reaction. At temperatures higher than $\mathrm{T}_{\mathrm{g}}$ of the PET backbone, the polymer acquires greater flexibility and, therefore, is more susceptible to the formation of free radicals.

Benzoyl peroxide (BP) was used as initiator, at higher BP concentration more active sites are formed on the fiber, leading to an increase in the grafting.

The increase in the monomer concentration increases the concentration of acrylic acid diffused into the PET fiber, but after certain values of monomer, the grafting yield decreased due to homopolymer formation on the PET surface.

These results also suggest that at a lower speed of monomer addition, the percentage of grafting decreases. At a low rate of acrylic acid addition, the radicals formed on the PET surface can react with other radical species present in the solution, inactivating the radicals and thus preventing the reaction.

The mechanism reported for the graft reaction between the acrylic acid on the polyester backbone, assumes that PET form two kinds of radicals when it is in contact with a radical initiating agent, $-\mathrm{CH}_{2}-\dot{\mathrm{C}} \mathrm{HOOCC}{ }_{6} \mathrm{H}_{4} \mathrm{COO}$ - is the predominant radical specie [21-23]. These radicals react with the methylene double bond present in the acrylic molecules, thereby carrying out the grafting reaction.

The highest obtained grafting was $23.5 \%$, which was achieved after $2 \mathrm{~h}$ of reaction by adding the monomer at a rate of $0.2 \mathrm{~mL} / \mathrm{min}$. This value was calculated by equation 1 . The polymer synthesized under these conditions was selected to continue the molecular imprinting process with the $\mathrm{BB}_{41}$.

$$
\text { Degree of grafting }=\frac{w_{g}-w_{0}}{w_{0}} \times 100
$$

where $\mathrm{W}_{\mathrm{g}}$ and $\mathrm{W}_{0}$ are the weight of the grafted and original PET fibers, respectively.

For the preparation of $\mathrm{MIPBB}_{41}$, a non-covalent imprinting approach was applied, with basic blue 41 as the template and PET-g-PAA as the support; the dye belongs to the azo group and has an imino group positively charged at $\mathrm{pH} 6$. The carboxylic acid group in the acrylic acid (functional monomer) interacted with the imine group (template) through electrostatic interactions. Thus, a specific binding site is formed in the polymers.

\section{Characterization}

FT-IR spectra were obtained for PET, PET- $g$-AA and MIPBB ${ }_{41}$. The vibrations of each polymer are shown in Table 1. Grafting of acrylic acid onto PET surface results in the appearance of a new absorption band at $2872 \mathrm{~cm}^{-1}$ corresponding to $\mathrm{C}-\mathrm{H}$ groups and a band at $3436 \mathrm{~cm}^{-1}$ related to the $\mathrm{O}-\mathrm{H}$ stretching of the carboxylic groups of acrylic acid due to the grafting of poly(acrylic acid) in the PET backbone. Additionally, the intensities of ether C$\mathrm{O}\left(1099 \mathrm{~cm}^{-1}\right)$ and $\mathrm{C}=\mathrm{O}\left(1715 \mathrm{~cm}^{-1}\right)$ bands increase with the grafting of acrylic acid in the polymeric network, as can also be seen by the broadening of those bands which were absent in the untreated polyester prior to grafting [21]. This result indicates that the modification process was carried out successfully [2223].
Table 1. Infrared vibrations $v\left(\mathrm{~cm}^{-1}\right)$ of PET, PET-g-AA y MIP.

\begin{tabular}{|c|c|c|c|}
\hline \multirow{2}{*}{ Vibration } & PET & PET-g-AA & MIP \\
\hline & 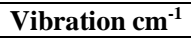 & 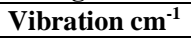 & Vibration $\mathrm{cm}^{-1}$ \\
\hline $\mathrm{ArC}-\mathrm{H}_{(\mathrm{w})}$ & 725.1 & 725.1 & 725.1 \\
\hline Ar C-H $(\mathrm{s})$ & 867.82 & 867.81 & 860.11 \\
\hline C-C-O (s asymm) & 1241.95 & 1245.79 & 1249.68 \\
\hline $\mathrm{C}-\mathrm{H}_{(\mathrm{b})}$ & 1411.66 & 1409.71 & - - - - \\
\hline $\mathrm{C}=\mathrm{O}_{(\mathrm{s})}$ & 1724.08 & 1712.48 & 1724.08 \\
\hline $\mathrm{C}-\mathrm{H}_{(\mathrm{s})}$ & 3062.46 & $\begin{array}{l}2872.01 \\
2983.34 \\
\end{array}$ & $\begin{array}{l}2962.17 \\
3062.46 \\
\end{array}$ \\
\hline $\mathrm{O}-\mathrm{H}(\mathrm{s})$ & $-\cdots$ & 3436.81 & $-\cdots$ \\
\hline $\mathrm{N}-\mathrm{H}_{(\mathrm{s})}$ & - . - & $\ldots$ & 3340.16 \\
\hline
\end{tabular}

For the MIP, comparison of the grafted and untreated polyester fibers shows that the most significant difference between their spectra is the band observed at $3340 \mathrm{~cm}^{-1}$, which is due to the stretching vibrations of the N-H bonds of the crosslinking agent.

Figure 1 shows the DSC thermograms obtained for the PET, PET- $g$-AA and MIP. This technique allowed us to identify structural modifications were carried out in the recycled PET in each synthesis stage.

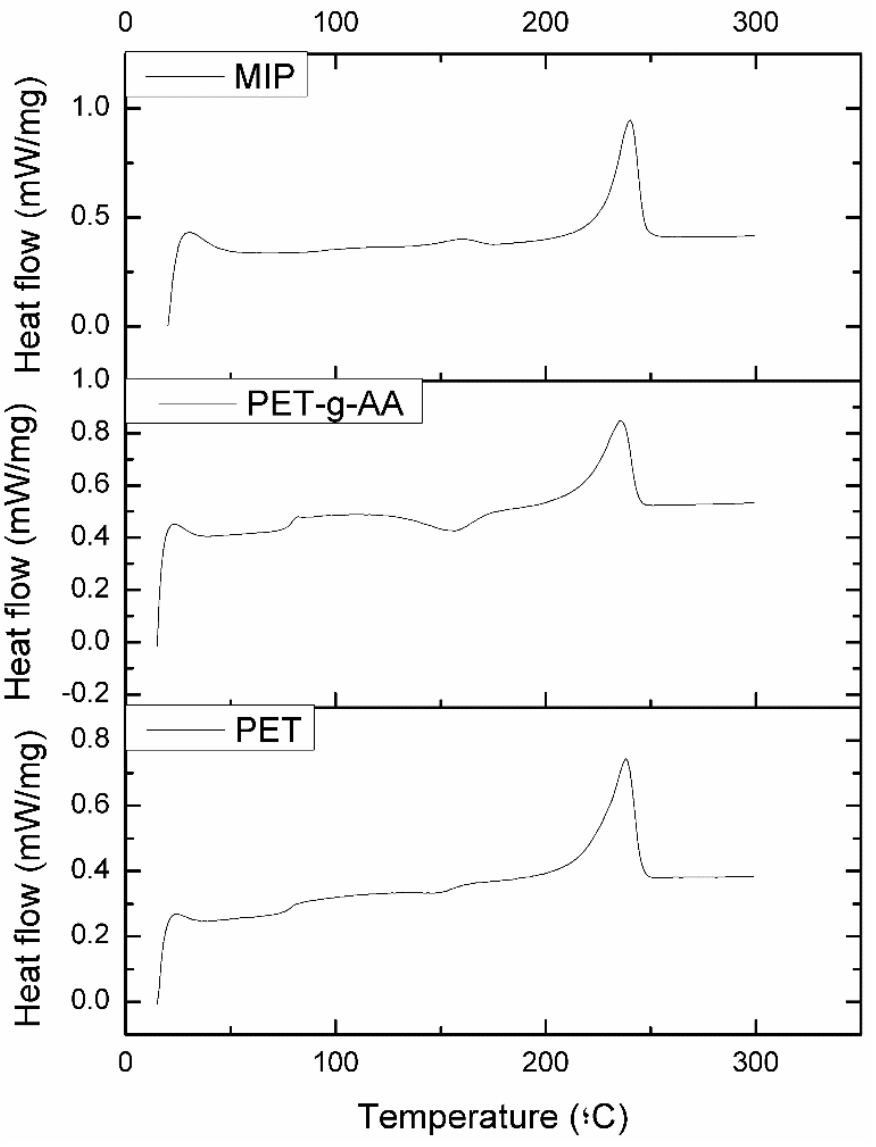

FIGURE 1. Thermograms of PET, PET- $g$-AA, and MIPBB ${ }_{41}$.

Changes in both the glass transition temperature $\left(\mathrm{T}_{\mathrm{g}}\right)$ and the melt temperature $\left(\mathrm{T}_{\mathrm{m}}\right)$ are observed in the thermograms due to structural changes in the polymer chains. The thermodynamic parameters $\left(\Delta \mathrm{H}_{\mathrm{m}}\right.$ and $\left.\Delta \mathrm{C}_{\mathrm{p}}\right)$ involved in each of the thermal transitions are also modified for each of the polymers. These values are summarized in Table 2, and it is observed that there are differences between the energies of the thermal transitions. These differences are due to the structural differences in the polymer chains, as the increase in the stiffness of the chain will require the application of additional energy to carry out the phase transitions [24-25]. 
$\mathrm{MIPBB}_{41}$ does not show a crystallization peak that is attributed to the increase in the degree of crystallinity of the polymer due to the formation of a crosslinked polymer network, which limits the mobility of the chains and favours the spatial ordering of the sample, significantly reducing the amorphous character of the polymer.

Table 2. Thermal transitions of PET, PET- $g$-AA and MIPBB41.

\begin{tabular}{|l|c|c|c|c|}
\hline Polymer & $\begin{array}{c}\mathbf{T}_{\mathbf{g}} \\
\left({ }^{\circ} \mathbf{C}\right)\end{array}$ & $\Delta \mathbf{C p}(\mathbf{J} / \mathbf{g} \mathbf{~ K})$ & $\begin{array}{c}\mathbf{T}_{\mathbf{m}} \\
\left({ }^{\circ} \mathbf{C}\right)\end{array}$ & $\begin{array}{c}\Delta \mathbf{H}_{\mathbf{m}} \\
(\mathbf{J} / \mathbf{g})\end{array}$ \\
\hline PET & 78 & 0.1 & 238 & 39 \\
\hline PET-g-AA & 77 & 0.2 & 236 & 37 \\
\hline MIP & 155 & & 240 & 49 \\
\hline
\end{tabular}

The morphologies of PET and PET- $g$-AA were studied by scanning electron microscopy (SEM), the micrographs of both materials under magnifications of $5000 \times$ and $1000 \times$ are shown in Figure 2.
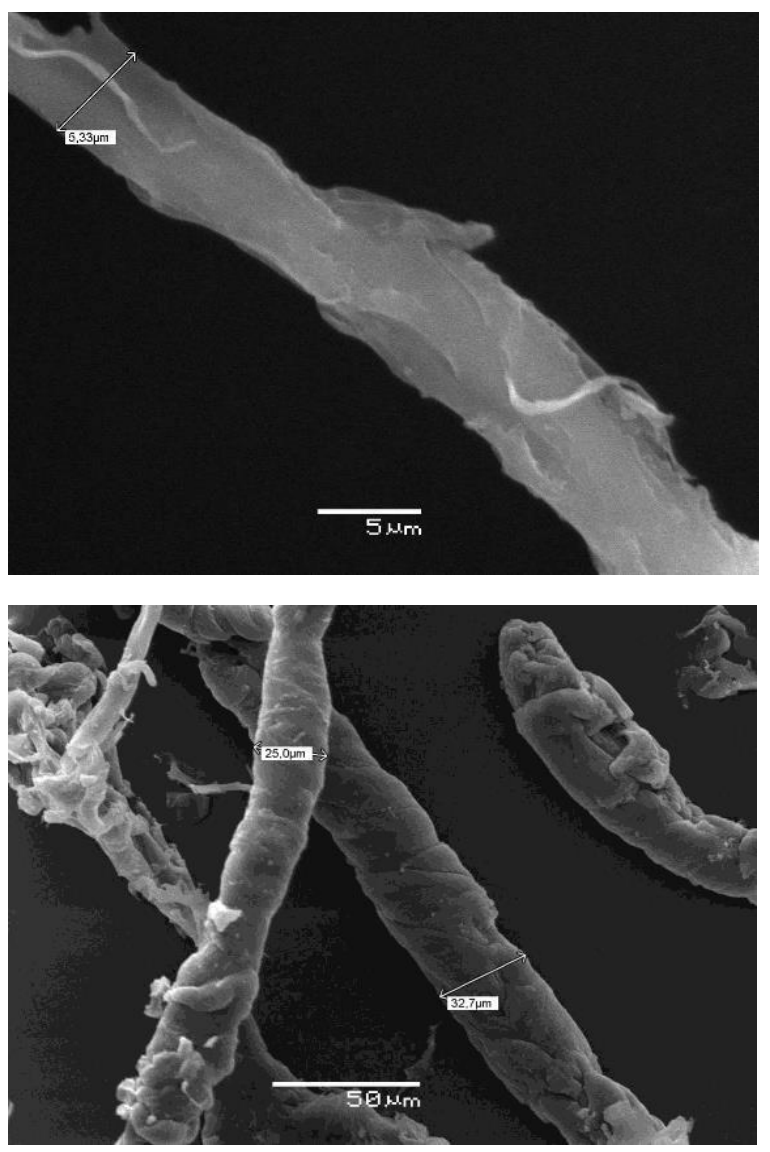

Figure 2. SEM micrographs of a)PET and b)PET- $g$-AA with 500x.

SEM micrographs of the grafted fibers show that the surface of the polyester fibers is smooth; however, after grafting the surface becomes uneven, and the growth of the graft can be observed on the surface of the fibers and in the increase in the diameter observed in SEM micrographs (see Figure 2), thus clearly showing that a layer of grafted poly(acrylic acid) was formed on the surface of these PET fibers. The diameter changes from 5.33 to approximately 25 micrometers for the grafted material.

\section{Adsorption studies}

The adsorption isotherm experiments for MIP were carried out for the $\mathrm{BB}_{41}$ concentration range of $20-500 \mathrm{mgL}^{-1}$ (see Figure 3). The amount of adsorbed dye per unit mass of the polymer increases with increasing initial concentration.

The graphs show "type s" isotherms, as the initial concentration increases the adsorption capacity. This is due to the process known as cooperative adsorption produced by associations between the adsorbed molecules [26-27].

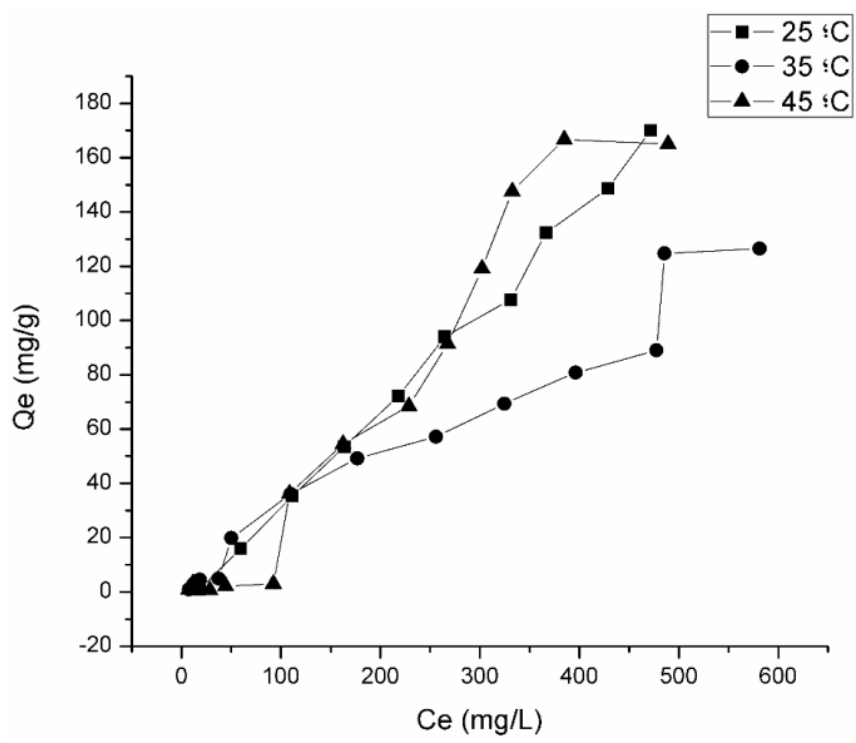

Figure 3. Adsorption isotherm for $\mathrm{BB}_{41}$ onto MIP at $25{ }^{\circ} \mathrm{C}, 35^{\circ} \mathrm{C}$, and $45^{\circ} \mathrm{C}$.

The experimental data were adjusted to the Langmuir model (see Figure 4), which shows that the adsorption process involves the formation of adsorbate monolayers on the surface of the adsorbent [28-29]. The Langmuir model is given by the following equation

$$
Q_{e}=\frac{Q_{\max } K_{L} C_{e}}{1+K_{L} C_{e}}
$$

where $\mathrm{Q}_{\mathrm{e}}$ is the adsorption capacity at equilibrium $(\mathrm{mg} / \mathrm{g}), \mathrm{C}_{\mathrm{e}}$ is the concentration at equilibrium $(\mathrm{mg} / \mathrm{L}), \mathrm{K}_{\mathrm{L}}$ is the affinity parameter $(\mathrm{mg} / \mathrm{L})$ and $\mathrm{Q}_{\max }$ is the maximum adsorption capacity. The Langmuir parameters are shown in Table 3.

Table 3. Equilibrium parameters for the Langmuir isotherm.

\begin{tabular}{|c|c|c|}
\hline $\mathbf{K}_{\mathbf{L}}$ & $\begin{array}{c}\mathbf{Q}_{\max } \\
(\mathbf{m g} / \mathbf{g})\end{array}$ & Regression coefficient $\left(\mathbf{r}^{2}\right)$ \\
\hline $1.03 \times 10^{-2}$ & 303 & 0.986 \\
\hline
\end{tabular}

The value of the affinity parameter smaller than 1 suggests a weak interaction between the adsorbate and the adsorbent, indicating that van der Waals forces or hydrogen bonds may be involved in the adsorption.

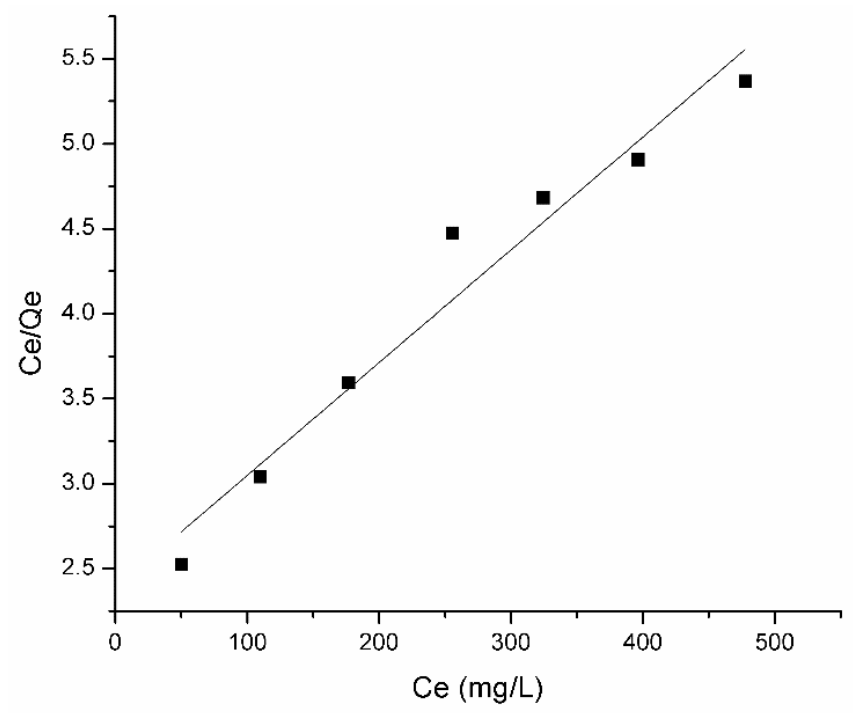

Figure 4. Langmuir isotherm for the adsorption of $\mathrm{BB}_{41}$ onto MIP. 
Based on the fitting of the experimental data to the Langmuir model, the dissociation constant $\left(\mathrm{K}_{\mathrm{d}}\right)$ and the specific site capacity $\left(\mathrm{Q}_{\max }\right)$ were determined from the slope and the intercept of the linear regression obtained from the Scatchard plots. The data were processed by Scatchard analysis according to the following equation:

$$
\frac{Q_{e}}{C_{e}}=\frac{Q_{\max }-Q_{e}}{K_{d}}
$$

where $Q_{e}$ is the adsorption capacity at equilibrium $(\mathrm{mg} / \mathrm{g}), \mathrm{C}_{\mathrm{e}}$ is the concentration at equilibrium $(\mathrm{mg} / \mathrm{L}), \mathrm{Q}_{\max }$ is the apparent maximum number of binding sites $(\mathrm{mmol} / \mathrm{g})$, and $\mathrm{Kd}$ is the dissociation constant.

Figure 5 shows the saturation binding curves for the imprinted polymer, in which two different regions can be observed with different slopes that can be fit by linear regressions. The presence of two regions indicates that the binding sites in the polymer structure are heterogeneous and have different affinities that can be described by two different dissociation constants corresponding to the high and low-affinity sites. The calculated parameters are shown in Table 4. These results are common for imprinted polymers when a non-covalent approach is used during the synthesis [30-31].

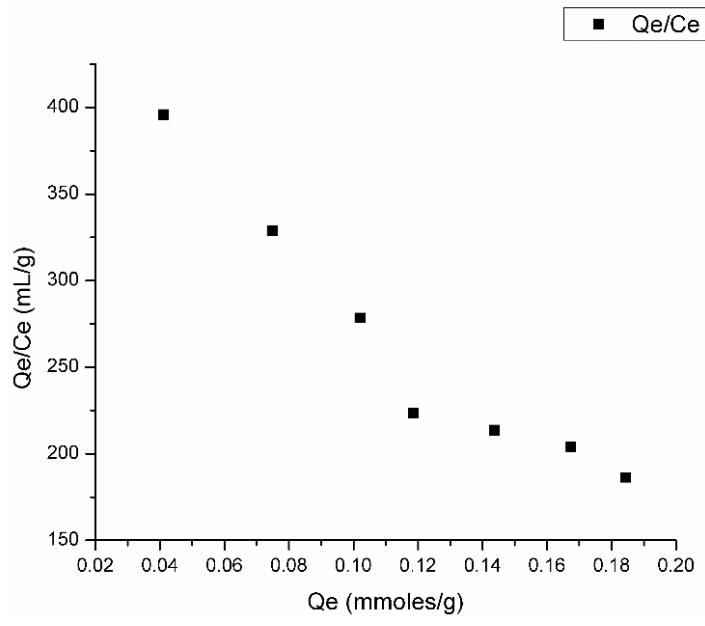

Figure 5. Scatchard plots for MIPBB 41 .

Table 4. Adsorption parameters for MIP.

\begin{tabular}{|c|c|c|c|c|c|}
\hline \multicolumn{2}{|c|}{ Linear regression } & \multirow{2}{*}{$\underset{(\mathrm{mol} / \mathrm{L})}{\mathrm{K}_{\mathrm{d} 1} \times 10^{-4}}$} & \multirow{2}{*}{$\begin{array}{c}\mathbf{Q}_{\max 1} \\
(\mathrm{mmol} / \mathrm{g})\end{array}$} & \multirow{2}{*}{$\underset{(\mathrm{mol} / \mathrm{L})}{\mathrm{K}_{\mathrm{d} 2} \times 10^{-4}}$} & \multirow{2}{*}{$\begin{array}{c}\mathbf{Q}_{\text {máx 2 }} \\
(\mathrm{mmol} / \mathrm{g}\end{array}$} \\
\hline High affinity & Low affinity & & & & \\
\hline $\begin{array}{c}\mathrm{Qe} / \mathrm{Ce}=487.74 \\
-2152.7 \mathrm{Q}\end{array}$ & $\begin{array}{c}\mathrm{Qe} / \mathrm{Ce}=229.06 \\
-389.73 \mathrm{Q}\end{array}$ & 4.65 & 0.227 & 25.6 & 0.5877 \\
\hline
\end{tabular}

The maximum adsorption capacity for the MIP was $144.8 \mathrm{mg} \cdot \mathrm{g}^{-1}$, comparing favorably with NMIP, for which the maximum adsorption capacity was 46.11 $\mathrm{mg} \cdot \mathrm{g}^{-1}$. The recognition coefficient was calculated according to:

$$
\propto_{r}=\frac{q_{M I P}}{Q_{N M I P}}=3.14
$$

The value of the recognition coefficient was greater than 1 . This coefficient indicates that MIP has greater affinity toward the dye due to the formation of specific sites that recognize the template molecule [32].

Adsorption assays confirmed that the molecular imprinting reaction was carried out satisfactorily, resulting in an increased affinity between the polymer and the template molecule.

\section{Selectivity studies}

Selectivity studies were carried out at room temperature at $\mathrm{pH} 6.2$ under agitation at $200 \mathrm{rpm}$. The adsorbent in contact with the template molecule in the presence of acid black 24 and acid blue 129, the structures of which are shown in Figure 6. a)
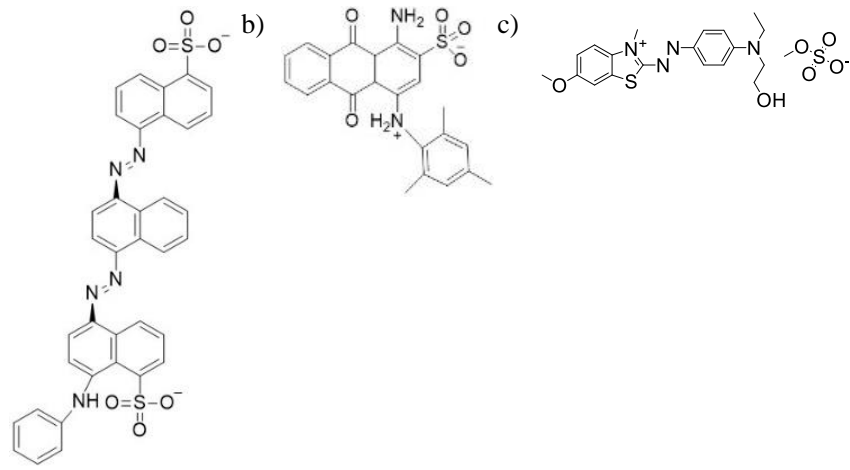

Figure 6. Chemical structures of a) acid black 24, b) acid blue 129 and c) Basic blue 41 .

The selectivity was evaluated by the calculation of the distribution constants $\left(\mathrm{K}_{\mathrm{d}}\right)$ and the selectivity coefficients $(\alpha)$ with the obtained values shown in Table 5. The obtained $\alpha$ value is greater than unity, indicating that MIP is selective toward basic blue 41 in the presence of dyes with similar structures. This result demonstrates a great advantage for the application of this adsorbent in effluents derived from the textile industry that contain a high amount of dyes that can interfere during the removal process.

Table 5. Selectivity parameters for MIP toward basic blue 41, acid black 24 and acid blue 129 .

\begin{tabular}{|l|c|c|}
\hline Dye & $\begin{array}{c}\text { Kd } \\
(\mathbf{m g} / \mathbf{L})\end{array}$ & $\boldsymbol{\alpha}^{*}$ \\
\hline Basic blue 41 & 6826 & -- \\
\hline Acid black 24 & 391.1 & 17.46 \\
\hline Acid blue 129 & 1317 & 5.180 \\
\hline
\end{tabular}

\section{CONCLUSIONS}

In this study a MIP was prepared from waste PET bottles and evaluated as the sorbent for the azoic dye basic blue 41 . The experimental data were successfully fitted to the Langmuir isotherm model. The maximum adsorption capacity under the studied experimental conditions was found to be $144.8 \mathrm{mgg}^{-1}$. The calculated recognition coefficient was 3.14 , indicating that the MIP exhibits high recognition toward the template molecule and that the imprinted polymer exhibits high selectivity toward the template molecule in presence of other dyes, thus, enabling its application for the removal of basic blue 41 from complex media with no interference.

\section{ACKNOWLEDGMENTS}

The authors are thankful to CONACyT for the scholarship number 336859, and to Universidad Autónoma de Nuevo León for the financial support to realize this research.

\section{REFERENCES}

1. Bassim, M. Removal of Textile Dyes (Maxilon Blue, and Methyl Orange) by Date Stones Activated Carbon. Int. Ad. Res. in Chem. Sci. 2014, 1, 48-59.

2. Bae, S.; Freeman, S.; Kim, D. Influences of new azo dyes to the aquatic ecosystem. Fiber Polym. 2006, 7, 30-35.

3. Abassi, M.; Asl, N. Sonochemical degradation of Basic Blue 41 dye assisted by nanoTiO $\mathrm{H}_{2}$ and $\mathrm{H}_{2} \mathrm{O}_{2}$. J. Hazard. Mater. 2008, 153, 942-947.

4. Roulia, M.; Vassiliadis, A. Interactions between C.I. Basic Blue 41 and aluminosilicate sorbents. J. Colloid Int. Sci. 2005, 291, 37-44.

5. Atar, N.; Olgun, A.; Çolak, F. Thermodynamic, Equilibrium and Kinetic Study of the Biosorption of Basic Blue 41 using Bacillus maceran. Eng. Life Sci. 2008, 5, 499-506.

6. Wong, Y.; Szeto, Y.; Cheung, W; McKay, G. Equilibrium Studies for Acid Dye Adsorption onto Chitosan. Langmuir. 2003, 19, 7888-7894.

7. Crini, G. Kinetic and equilibrium studies on the removal of cationic dyes from aqueous solution by adsorption onto a cyclodextrin polymer. Dyes and Pigments. 2008, 2, 415-426. 
8. Rafatullah, M.; Sulaiman, O.; Hashim, R.; Ahmad, A. Adsorption of methylene blue on low-cost adsorbents: A review. J. Haz. Mater. 2010, 177, 70-80.

9. Ngah, W.; Teong, C.; Hanafiah, M. Adsorption of dyes and heavy metal ions by chitosan composites: A review. Carb. Polym. 2011, 83, 1446-1456.

10. Qiu, H.; Lv, L.; Pan, B.; Zhang, Q.; Zhang, W.; Zhang, Q. Critical review in adsorption kinetic models. J. Zhejiang Univ-SCI A. 2009, 10, 716-724.

11. Wang, W.; Xie, Y.; Zhang, Y.; Tang, S.; Guo, C.; Wu, J.; Lau, R. Anionic and cationic dyes adsorption on porous poly-melamine-formaldehyde polymer Chem. Eng. Res. Des. 2016, 114, 258-267.

12. Fu, J.; Xin, Q.; Wu, X.; Chen, Z.; Yan, Y.; Liu, S.; Wang, M.; Xu, Q. Selective adsorption and separation of organic dyes from aqueous solution on polydopamine microspheres. J. Coll. Inter. Sci. 2016, 461, 292-304.

13. Lin, Q.; Gao, M.; Chang, J.; Ma, H. Adsorption properties of crosslinking carboxymethyl cellulose grafting dimethyldiallylammonium chloride for cationic and anionic dyes. Carb. Polym. 2016, 151, 283-294.

14. Nicholls, I.; Ramström, O.; Mosbach, K. Insights into the role of the hydrogen bond and hydrophobic effect on recognition in molecularly imprinted polymer synthetic peptide receptor mimics. J. Chromat A. 1995, 691, 349-353.

15. Sharma, P.; Iskierko, Z.; Pietrzyk-Le, A.; D’Souza, F.; Kutner, W. Bioinspired intelligent molecularly imprinted polymers for chemosensing: A mini review. Electrochem. Commun. 2015, 50, 81-87.

16. Shahar, T.; Tal, N.; Mandler, D. Molecularly imprinted polymer particles: Formation, characterization and application. Coll. Surf. A. 2016, 495, 11-19.

17. Iskierko, Z.; Sharma, P.; Bartold, K.; Pietrzyk-Le, A.; Noworyta, K.; Kutner, W. Molecularly imprinted polymers for separating and sensing of macromolecular compounds and microorganisms. Biotech. Adv. 2016, 34, 30-46.

18. Gama, M.; Bottoli, C. Molecularly imprinted polymers for bioanalytical sample preparation. J. Chromat. B. 2017, 1043, 107-121.

19. Figueiredo, L.; Erny, G., Alves, L. Applications of molecularly imprinted polymers to the analysis and removal of personal care products: A review. Talanta, 2016, 146, 754-765.

20. Sarafraz-Yazdi, A.; Razavi, N. Application of molecularly-imprinted polymers in solid-phase microextraction techniques. Trends Anal. Chem. 2015, 73, 81-90.

21. Campbell, D.; Araki, K.; Turner, D. ESR study of free radicals formed by $\gamma-$ irradiation of poly(ethylene terephthalate). J. Polym. Sci. Part A. 1966, 4, 2597-2606.
22. Rath, S.; Patri, M.; Sharma, S.; Sudarshan, K.; Pujari, P. Free volume and microstructural investigation of poly(ethylene terephthalate)-g-acrylic acid (PET-g-AA) copolymer films. Rad. Phys. Chem. 2010, 79, 745-750.

23. Ping, X.; Wang, M.; Ge, X. Surface modification of poly(ethylene terephthalate) (PET) film by gamma-ray induced grafting of poly(acrylic acid) and its application in antibacterial hybrid film. Rad. Phys. Chem. 2011, $80,567-572$.

24. Litvinov, V.; Barthel, H.; Weis, J. Structure of a PDMS Layer Grafted onto a Silica Surface Studied by Means of DSC and Solid-State NMR. Macromol. 2002, 35, 4356-4363

25. Sulitzky, C.; Rückert, B.; Hall, A.; Lanza, F.; Unger, K.; Sellergren, B. Grafting of Molecularly Imprinted Polymer Films on Silica Supports Containing Surface-Bound Free Radical Initiators. Macromol. 2002, 35, 7991.

26. Perić, J.; Trgo, M.; Medvidović, N. Removal of zinc, copper and lead by natural zeolite - a comparison of adsorption isotherms. Water Res. 2004, 38, 1893-1899.

27. Rouquerol, J.; Rouquerol, F.; Llewellyn, P.; Maurin, G.; Sing, K. Adsorption by powders and porous solids: principles, methodology and applications. Elsevier: Oxford; pp 11-14.

28. Umpleby, R.; Baxter, S.; Chen, Y.; Shah, R.; Shimizu, K. Characterization of molecularly imprinted polymers with the Langmuir-Freundlich isotherm. Anal. Chem. 2001, 73, 4584-4591.

29. Umpleby, R.; Baxter, S.; Bode, M.; Berch, J.; Shah, R.; Shimizu, K. Application of the Freundlich adsorption isotherm in the characterization of molecularly imprinted polymers. Anal. Chim. Acta. 2001, 435, 35-42.

30. Guo, H.; He, X. Study of the binding characteristics of molecular imprinted polymer selective for cefalexin in aqueous media. Fresenius $\mathrm{J}$ Anal Chem, 2000, 368, 461-465.

31. Takeuchi, T.; Mukawa, T.; Matsui, J.; Higashi, M.; Shimizu, D. Molecularly Imprinted Polymers with Metalloporphyrin-Based Molecular Recognition Sites Coassembled with Methacrylic Acid. Anal. Chem. 2001, 73, 38693874.

32. Zhao, C., Zhao, T.; Liu, X.; Zhang, H. A novel molecularly imprinted polymer for simultaneous extraction and determination of sudan dyes by online solid phase extraction and high performance liquid chromatography. J. Chromat. A. 2010, 1217, 6995-7002. 